\title{
Debates entre Pais e Mães Divorciados: Um Trabalho com Grupos
}

Discussion Among Divorced Parents:

Working with Groups

Discusiones entre los Padres y las Madres Divorciados: un Trabajo con Grupos

Leila Maria Torraca de Brito, Andréia Ribeiro Cardoso \& Juliane Dominoni Gomes de Oliveira

Universidade do Estado do Rio de Janeiro
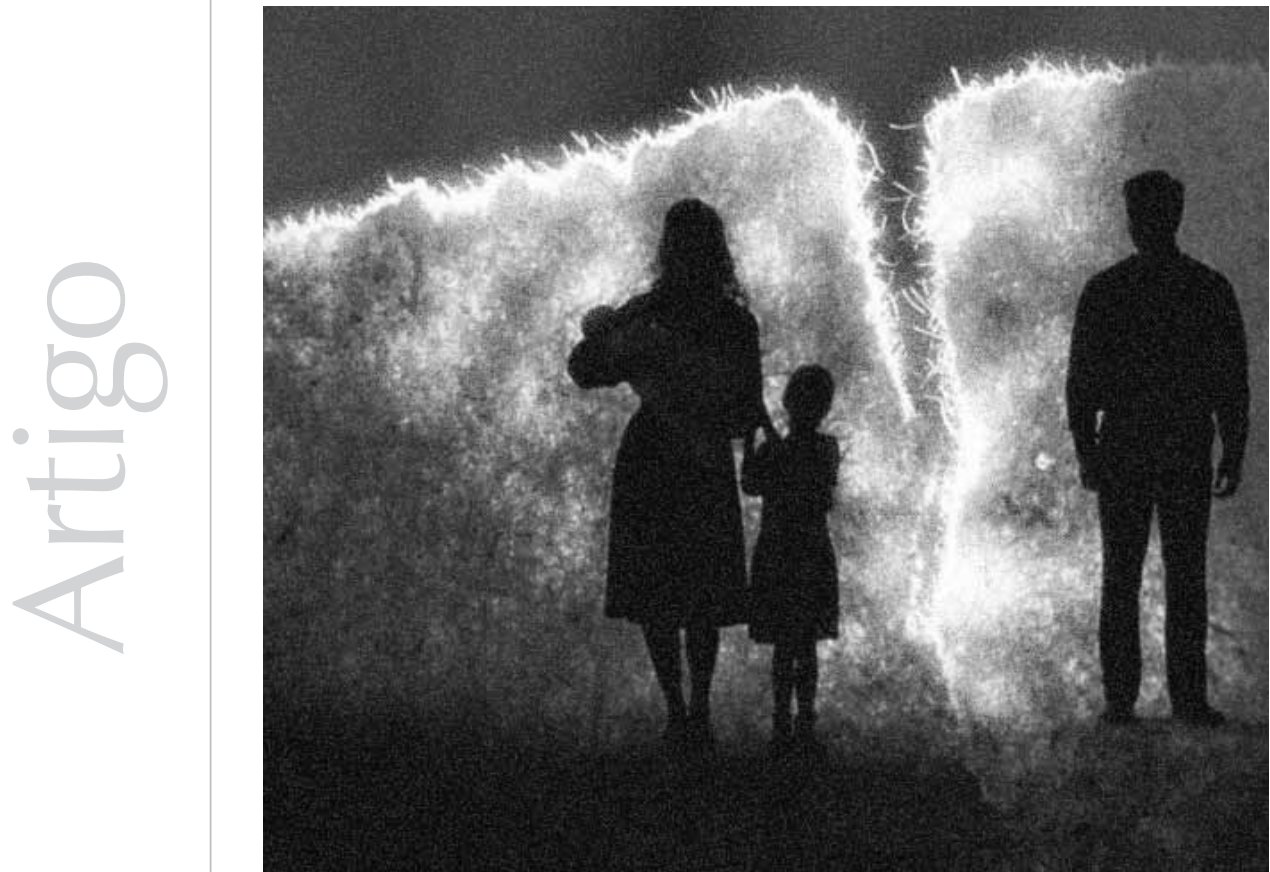
Resumo: $O$ artigo apresenta dados coletados em pesquisa participativa realizada por meio de grupos de reflexão com pais e mães separados. A investigação teve como objetivo avaliar dificuldades quanto ao exercício da parentalidade após a separação conjugal bem como a possibilidade do uso de grupos de reflexão em tais situações. Destacam-se, no artigo, vivências e queixas de pais e de mães que participaram de cada um dos dois grupos organizados no que diz respeito ao convívio com os filhos após a dissolução conjugal. Conclui-se que a divisão tradicional entre guardiães e visitantes acarreta dificuldades próprias a cada uma das categorias, o que pode ser bem compreendido quando os pais se reúnem para o debate sobre o tema. Palavras-chave: Divórcio. Relações pais-filhos. Pesquisa participativa. Psicologia forense.

Abstract: The article presents data collected in participatory research through groups of reflections with divorced parents. The investigation had as scope the evaluation of the difficulties towards parenthood after the couple's separation as well as the possibilities and improvements achieved through the groups of reflection. It is pointed out in this work the life and the complaints of fathers and mothers who participated in both groups referring to their living and social relationships with their children after separation. It is concluded that the traditional division between custodians and no custodial parents brings special difficulties to each one of these categories that may be better comprehended when parents come to groups of discussions on this matter.

Keywords: Divorce. Parent child relationships. Participant research. Forensic psychology.

Resumen: El artículo presenta dados colectados en investigación participativa efectuada por medio de grupos de la reflexión con los padres y las madres divorciados. La investigación tenía como finalidad evaluar dificultades cuánto al ejercicio de la parentalidad después de la separación conyugal, así como la posibilidad del uso de grupos de la reflexión en tales situaciones. Son distinguidos, en el artículo, las experiencias e las quejas de los padres y de las madres que habían participado en cada uno de los grupos organizados, en lo que dice respecto a la convivencia con los niños después de la disolución conyugal. Concluye que la división tradicional entre los guardianes y los visitantes causa dificultades a cada uno de las categorías, qué puede ser entendido mejor cuando los padres si reúnen para el discusión sobre el tema.

Palabras clave: Divorcio. Relaciones padres-hijos. Investigacion participante. Psicologia forense.

A separação conjugal é identificada como um acontecimento responsável por inúmeras mudanças no cotidiano dos que compõem o grupo familiar, especialmente quando o casal possui filhos, e gera, por vezes, dúvidas e insatisfações quanto ao relacionamento de cada um dos pais com as crianças. Com frequência desponta a questão: quando o casal conjugal desaparece, como os papéis parentais devem ser mantidos? Ou ainda, agora, quem será responsável pela educação das crianças?

Em pesquisa realizada pelo Children of Divorce Project, Wallerstein e Kelly (1996/1998) observaram a desorientação de muitos genitores quanto ao comportamento com os filhos após a separação conjugal. Para as autoras citadas, dependendo das causas

${ }^{1} \mathrm{No}$ artigo em questão, separação conjugal e divórcio não foram diferenciados. que conduziram ao divórcio ${ }^{1}$, muitos adultos precisam de ajuda e de esclarecimentos para melhor definir e executar os acordos referentes aos filhos bem como para exercer a paternidade ou a maternidade após o desenlace conjugal. As autoras notaram também que, constantemente, pais e mães compareciam às entrevistas munidos de cadernos de anotações, em decorrência de uma série de dúvidas que gostariam de esclarecer. Tal demanda motivou os que atuavam no projeto a oferecer atendimento aos pais na forma de aconselhamento psicológico, que foi interpretado pelos participantes como de suma importância na medida em que sentiam necessidade, logo após o divórcio, de parâmetros para refletir sobre as novas formas de interação familiar.

Estudiosos do tema (Durning, 1996; Gillot, 1998) vêm sustentando que, em consequência das dificuldades relatadas por pais e mães que se divorciam, Ihes deve ser oferecido um espaço de escuta, que pode ser uma biblioteca, um hospital ou até mesmo um local nas instalações do Poder Judiciário. Como afirma Décoret (2001), após 
o desenlace conjugal, não se deve perder de vista que os filhos são "uma parte daquela ou daquele que não é mais nada para você e pode mesmo vir a ser um adversário" (p. 44). Adverte o autor que não se pode desprezar que, quer o pai ou a mãe da criança gostem ou não, o ex-cônjuge continua a existir na vida dos filhos.

No Brasil, apesar de promulgada a lei sobre a guarda compartilhada em 2008, ainda são visíveis as contrariedades em relação ao emprego da mesma, como destacam Brito e Gonsalves (2009). Dessa maneira, com maior frequência se atribui a guarda das crianças a um dos pais, permanecendo o outro genitor com a incumbência de supervisionar os interesses dos filhos, como disposto no $\$ 3$ o do artigo 1583 do Código Civil Brasileiro.

Diversos autores (Bruno, 2003; Pereira, 2003), entretanto, alertam para as dificuldades que podem surgir com a guarda monoparental na medida em que o genitor que não reside com os filhos pode se sentir afastado do cotidiano dos mesmos, enquanto aquele a quem se atribuiu o papel de guardião se vê com maiores atribuições no cuidado e na educação da prole. Os autores consideram, contudo, que a relação entre pais e filhos é mantida por meio de um contato frequente, sendo reconhecido, atualmente, o direito das crianças à convivência familiar, como disposto no Estatuto da Criança e do Adolescente (1990).

Visando à contribuição sobre o debate referente à convivência familiar após o divórcio, desenvolveu-se pesquisa participativa com pais e mães separados quando, por meio de grupos de reflexão, buscou-se apreender como vem se configurando o relacionamento entre pais e filhos após o desenlace conjugal dos primeiros. Como expõem Soares, Martins, Butler, Caldeira e Rizzini (2003): "As pesquisas qualitativas e participativas vêm sendo potencializadas, reconhecendo- se sua capacidade de explicação ao interrelacionar diferentes aspectos da situação estudada" (p. 125). Na investigação em pauta, teve-se também como objetivo analisar a aplicabilidade dos grupos de reflexão em tais situações, trabalho que será apresentado a seguir.

\section{Investigações por meio do trabalho com grupos}

Ao proceder à revisão da literatura sobre as pesquisas empreendidas a partir de grupos com pessoas divorciadas, verificou-se que, com certa frequência, se utilizam procedimentos separados para o levantamento de dados com mulheres e com homens. Como exemplo, podem-se citar os grupos de mães separadas oferecidos pelo Instituto de Terapia de Família, no Rio de Janeiro (Rapizo, Falcão, Costamilan, Scodro, \& Moritz, 1998), que faziam parte de investigação sobre a construção da parentalidade pós-divórcio. Em contrapartida, podem-se citar os grupos de reflexão com homens que eram pais, desenvolvidos por Muzio (1994), e os grupos com jovens do sexo masculino que não possuíam a guarda dos filhos, que Lehr e Macmillan (2001) utilizaram como metodologia para a coleta de dados na pesquisa que desenvolveram.

De forma distinta desses últimos autores - e à semelhança da investigação descrita por Décoret (2001) -, a pesquisa a ser aqui relatada reuniu, em grupos de reflexão, pais e mães separados para discutir questões próprias ao exercício da parentalidade. Destaca-se que os grupos não foram formados por ex-casais, mas por pessoas separadas, com filhos, independentemente do fato de disporem ou não da guarda parental. Partiu-se do entendimento de que a metodologia de pesquisa participativa alcança dois objetivos principais: produzir conhecimentos e mudar a realidade pela ação, como explica Rose (2001). No movimento do grupo, dificuldades 
Acosta,

Andrade Filho e Bronz (2004), pesquisadores que vêm sistematizando o uso de grupos de reflexão com homens acusados de terem cometido violência doméstica: "o grupo reflexivo constitui-se como um espaço de inclusão dos sentimentos, da subjetividade e das relações em um sistema grupal de convivência e reflexão" (p. 23). e esclarecimentos se mesclam no decorrer dos encontros, facilitando maior discernimento da realidade vivenciada por meio da troca de informações, saberes e experiências.

Nessa técnica de pesquisa, os participantes também podem discutir e apresentar alternativas para lidar com suas dificuldades, favorecendo-se novas formas de comportamento e significado para atitudes e conceitos pré-concebidos. Como descrevem Acosta, Andrade Filho e Bronz (2004), pesquisadores que vêm sistematizando o uso de grupos de reflexão com homens acusados de terem cometido violência doméstica: “o grupo reflexivo constitui-se como um espaço de inclusão dos sentimentos, da subjetividade e das relações em um sistema grupal de convivência e reflexão" (p. 23).

Teubal (2005) reconhece que, no trabalho com grupos, há fatores que "podem contribuir para gerar aprendizagens e mudanças na subjetividade e, em alguma medida, diminuir o trauma ocasionado pelas condições de existência" (p. 14), acrescentando ainda que não basta uma boa execução do grupo ou um perfeito planejamento e definição de objetivos para que se conclua que houve êxito. Na visão dessa autora, ao se avaliar o trabalho realizado com grupos, deve-se questionar, constantemente, se houve algum tipo de transformação e qual o impacto que se pode observar nos seus integrantes, orientação que se buscou seguir.

\section{Metodologia}

A realização dos grupos de reflexão com pais e mães separados foi precedida de uma série de ações, próprias de pesquisas participativas, no que diz respeito à preparação das reuniões, à escolha do material de apoio a ser utilizado, à capacitação dos membros da equipe, à divulgação dos grupos e à seleção dos participantes. Foi definido que os encontros dos grupos, com frequência semanal, seriam realizados nas dependências da universidade. Cada grupo teria doze encontros de uma hora e meia que deveriam ocorrer no período noturno, o que corresponderia a uma duração de três meses. Os grupos de reflexão deveriam reunir pais e mães separados no total de, no máximo, dez participantes por grupo. Era indiferente o fato de os candidatos possuírem ou não a guarda dos filhos.

Um plano de trabalho inicial foi elaborado, com o planejamento de cada encontro. Foram selecionados os temas a serem discutidos, as dinâmicas a serem utilizadas e o material audiovisual necessário, como crônicas e trechos de filmes e músicas. Tarefas individuais e em grupo também foram recursos empregados nos encontros. Convites para a participação nos grupos foram divulgados em sites de organizações de pais e mães separados e em pequenos cartazes fixados na instituição de ensino, e as inscrições foram feitas a partir de um e-mail criado pela equipe de pesquisa. Nos convites, a única condição explicitada era a de os candidatos serem pais ou mães separados, não havendo qualquer indicação quanto à idade, à classe social ou à escolaridade. Após as inscrições, procedeu-se às entrevistas individuais quando os objetivos do grupo e as características de seu funcionamento foram explicados aos candidatos. Naquele momento, foram avaliadas as expectativas dos inscritos quanto ao trabalho a ser desenvolvido, colhendo-se também dados de identificação dos mesmos. Notou-se que alguns candidatos não se encaixavam na condição solicitada - ou seja, o de pais ou mães separados -, expondo-se, para estes, o motivo que impossibilitava sua admissão nos grupos.

Seguindo orientações próprias à ética em pesquisas, foi estruturado o Termo de Consentimento Livre e Esclarecido, lido e explicado já no primeiro encontro de cada grupo, quando foi assinado pelos participantes. Um termo de convivência 
foi construído pelos membros dos grupos, que estabeleceram consensualmente as respectivas regras de funcionamento. Além dos pais e mães separados, estavam presentes nos encontros três membros da equipe de pesquisa, sendo duas coordenadoras e um bolsista de iniciação científica, este último responsável pelo registro de cada encontro.

A equipe de pesquisa se reunia duas vezes por semana. Na primeira etapa, eram feitas a leitura e a análise inicial dos dados registrados no encontro anterior do grupo de reflexão, e, na segunda reunião da equipe, planejava-se o próximo encontro dos pais. Cabe destacar que, apesar de haver um planejamento inicial no qual estava previsto o enfoque a ser privilegiado em cada encontro dos pais, a definição dependia das avaliações precedentes. A pesquisa foi desenvolvida com dois grupos sucessivos, do qual participaram dezesseis sujeitos - onze homens e cinco mulheres -, de classe média, com idades entre 30 e 55 anos, que residiam no Rio de Janeiro.

O primeiro grupo reuniu nove integrantes, sendo sete pais e duas mães, e o segundo contou com sete candidatos, sendo quatro pais e três mães com filhos em distintas faixas etárias. Houve desistências, pois, como reconhecem Rapizo, Costamilan, Moritz e Hinds (2001), "o grupo leva algum tempo para estabilizar o número de participantes, o que se dá naturalmente, dependendo da utilidade que terá para cada um" ( $p$. 38). Assim, no primeiro grupo, houve uma desistência, e, no segundo, duas.

Os dados coletados por meio dos grupos foram avaliados de acordo com a técnica de análise de conteúdo (Bardin, 1977). Posteriormente, a pedido dos participantes, foi realizado um encontro com todos os que integraram os dois grupos - momento em que se esclareceu como estavam sendo divulgados os primeiros resultados da pesquisa.

\section{Resultados e discussão}

Apesar de Wallerstein, Lewis e Blakeslee (2000/2002) afirmarem ser mais comum, na realização de pesquisas, obter o relato de mulheres pelo fato de estas se sentirem "mais à vontade para discutir relacionamentos" (p. 53), o número de pais inscritos nos grupos de reflexão oferecidos foi superior ao de mães. Os próprios homens se mostraram surpresos pela elevada representação masculina nos grupos, levantando como hipótese para essa maior procura o fato de os pais sofrerem mais com as consequências da separação, pois, frequentemente, não permanecem com a guarda dos filhos, encontrando-os apenas de quinze em quinze dias. Reconheceram que a sociedade ainda vê o pai como o principal provedor da prole, e a mãe, como aquela que cuida, abdicando de tudo pelas crianças, o que explica o elevado número de guardas atribuído às mães, conforme indicam estatísticas nacionais (Instituto Brasileiro de Geografia e Estatística [IBGE], 2005).

Em relação ao estabelecimento da guarda dos filhos, alguns participantes do grupo já a haviam acertado, enquanto outros figuravam como partes em processos judiciais para a sua definição ou para alterar a visitação. Na época em que foram realizados os grupos, apenas um dos homens residia com os filhos e uma entre as mulheres não morava na companhia da prole. Os outros eram mães guardiãs e pais que não possuíam a guarda, como geralmente ocorre após o rompimento conjugal.

No decorrer dos grupos, os integrantes, solidários em alguns momentos e críticos em outros, trocavam conselhos, faziam comentários sobre os problemas que vivenciavam e sugeriam alternativas de comportamento. Nesse movimento, alguns, indignados, reprovavam o que compreendiam como submissão de outros participantes aos caprichos e regras criados por ex-cônjuges, propondo comportamentos individuais 
diferenciados; outros argumentavam que muitos ali possuíam problemas semelhantes, convidando o grupo a encaminhar propostas e ações coletivas com abrangência social.

\section{Impactos do aspecto conjugal sobre o exercício da maternidade e da paternidade}

Nos primeiros encontros dos grupos, os participantes demonstraram grande necessidade de relatar o difícil relacionamento que mantinham com o ex-cônjuge, seus descontentamentos e frustrações e o quanto essas dificuldades acabavam relacionadas ao exercício da maternidade e da paternidade. Sobressaía, em seus discursos, a expressão das relações conflituosas entre o ex-casal. Tanto os que permaneceram com a guarda dos filhos como aqueles que não a possuíam compreendiam que essas situações traziam uma série de perturbações às suas vidas, considerando que a raiva e a mágoa relativas ao cônjuge acabavam interferindo no convívio com os filhos. A distinção entre os aspectos próprios da convivência com o cônjuge e os que dizem respeito aos filhos surgiu como uma necessidade, sendo avaliado posteriormente pelos participantes como o mais relevante assunto a ser abordado nesse tipo de trabalho.

Nos encontros, por vezes, ocorria um enfrentamento entre os homens e as mulheres, mesclando-se frases sérias com piadas sobre os comportamentos masculinos e femininos. Nas várias discussões travadas, houve destaque para as relações de gênero, evidenciando-se uma série de estereótipos que se estendiam ao que consideravam papéis maternos e paternos. Quanto a esse aspecto, Connel (1995/2003) afirma que: "Reconhecer o gênero como um padrão social nos exige vê-lo como um produto da História e também como um produtor da História" (p. 46).
Os homens deixavam claro que, para eles, a separação, além de não extinguir os conflitos com a ex-esposa, lhes trouxe uma descontinuidade no convívio com os filhos. Dessa forma, problemas decorrentes do rompimento conjugal pareciam intermináveis, contrariando o que comumente é dito - que a separação resolve brigas e desentendimentos. Compreendiam que as batalhas apenas haviam mudado de foco, centrando-se, agora, na disputa pela convivência com os filhos, o que os afetava intensamente, situação também identificada por Lehr e Macmillan (2001). Sentiam-se, assim, exauridos e marcados pelo resto de suas vidas, em uma luta que parecia sem fim. Destacaram, ainda, que, no momento inicial da dissolução conjugal, não ficara claro que, com a decisão, haveria um grande afastamento dos filhos, na medida em que logo após saírem de casa já eram designados como visitas. Esclareceram que, no início do rompimento, a questão girava apenas em torno do aspecto conjugal, e só quando deixavam o lar é que iam procurar parâmetros para o relacionamento com os filhos. Para isso, buscaram advogados, familiares e amigos, visando ao auxílio nos procedimentos em relação às crianças. Os pais indicaram que, quase sempre, recebiam como resposta a velha fórmula: homens não ficam com a guarda e devem se acostumar a ver os filhos de quinze em quinze dias. Só depois é que verificaram não ser possível manter vínculos estreitos com os filhos por meio de visitas quinzenais, medida que interfere na intimidade que deve ser mantida com as crianças. Como bem define Muzio (1994): "As cargas culturais promovem para o homem uma paternidade representativa (enquanto autoridade, provedor do lar) e periférica (à distância)" (p. 31).

Ao longo das discussões, foi consenso entre pais e mães o fato de muitas mulheres se sentirem como as únicas responsáveis pelos filhos ao considerarem que, apesar da sobrecarga, podem cuidar e educar suas 
crianças sozinhas - o que, de alguma forma, as leva a restringir a participação e o contato dos ex-maridos com a prole. Muitos homens se sentiam apenas provedores financeiros dos filhos e expressavam que gostariam de vê-los mais amiúde, relato que surpreendeu algumas mulheres dos grupos que afirmavam desconhecer o sofrimento de homens por não estarem assiduamente com os filhos. Nesses momentos, certo número de mães advertiu sobre a impossibilidade de generalizações, pois também conheciam diversos homens que não procuravam manter contato com as crianças ou que não possuíam a mesma disponibilidade dos que estavam no grupo, concluindo pela inadequação de uma visão naturalizada de comportamentos vistos como masculinos e femininos.

Alguns participantes dos grupos disseram que, se tivessem pensado melhor ou recebido alguma orientação no momento em que decidiram se separar, esse fato talvez não tivesse ocorrido, sugerindo, por vezes, que a separação tenha sido uma decisão intempestiva. Esses participantes faziam questão de ressaltar que, agora, compreendiam não haver um mal-estar no casamento que perdurasse por longo tempo ou uma forte razão que motivasse o divórcio, reconhecendo que as separações haviam ocorrido por motivos que atualmente consideravam banais.

\section{Os arranjos de guarda}

Grande parte dos integrantes dos grupos entendia que as disposições jurídicas na busca pelo genitor que apresente melhores condições para permanecer com a guarda dos filhos - indicação prevista no Código Civil Brasileiro no caso da guarda monoparental - acabam por acirrar a disputa entre o pai e a mãe da criança, conforme já apontado por Brito (2002). Quanto a esse item, alguns homens advertiam que um pai só obtém a guarda dos filhos "se a mãe das crianças for maluca, prostituta ou usar drogas". Os pais canadenses que participaram da investigação conduzida por Lehr e MacMillan (2001) também afirmaram que, naquele país, só em três situações os homens conseguem, sem dificuldades, a guarda dos filhos: quando "a mãe abusa da criança, usa drogas ou é alcoólatra" (p. 376). Mesmo tendo ciência de que poucas seriam as chances de conseguir a guarda das crianças, muitos homens que participaram dos grupos de reflexão relataram que insistiam na disputa para que, mais tarde, os filhos soubessem que lutaram por eles. Outros, porém, já desgastados pelas brigas, questionavam se todo o esforço para estarem mais próximos aos filhos seria salutar ou se deveriam apenas deixar as ex-mulheres cuidando da prole, procedimento adotado por muitos que conheciam.

Alguns pais revelaram que lidar com a rejeição dos filhos referente a eles era extremamente penoso, reconhecendo que faziam grande esforço para não desistir nesse momento. Quanto a esse ponto, certas mães admitiram que, por vezes, os filhos não se relacionam bem com os pais para agradá-las. Na pesquisa desenvolvida por Wallerstein e Kelly (1996/1998, p. 144), as autoras também notaram que metade dos homens que entrevistaram temia a rejeição dos filhos.

Pais e mães lamentaram a morosidade na tramitação dos processos na Justiça, justificando que, por esse motivo, muitas situações acabavam por se consolidar. Explicaram que o fato de a separação do casal ter sido consensual não significava que houvesse bom relacionamento com o ex-cônjuge ou adequado procedimento de visitação. Os pais que não permaneceram com a guarda revelaram que os problemas para o acesso aos filhos, inclusive por telefone, tiveram início depois de acertada a visitação, o que os deixava extremamente magoados. Os integrantes dos grupos demonstraram forte expectativa de que questões relativas 
ao acesso aos filhos fossem abordadas em audiências realizadas nos Juízos de Família, sugerindo que equipes técnicas do Judiciário centrassem seu trabalho na orientação de pais e mães para que ambos pudessem conviver com os filhos após a separação.

Assim como nos grupos que Lehr e MacMillan (2001) realizaram com homens que não possuíam a guarda dos filhos, os que participaram da pesquisa aqui relatada queixaram-se do que denominavam discriminação em relação aos homens, ou seja, menos direitos no que concerne aos filhos, sugerindo que os responsáveis não são considerados iguais pela sociedade. Quanto a esse aspecto, pode-se recordar que a juíza Maria Lúcia Karan (1998) ressalta que:

a concretização do princípio da igualdade entre homens e mulheres, expressamente consagrado no artigo 5으, inciso I da Constituição Federal, passa necessariamente pelo estabelecimento de uma nova forma de relacionamento entre pais e filhos, em que o papel do pai não seja mais o de um simples coadjuvante, dividindo sim, com a mãe, as funções de criação e educação dos filhos. (p. 189)

Por outro lado, o grupo também discutiu a sobrecarga do genitor guardião que, além de acumular atribuições, acaba assumindo o papel exclusivo de cuidador dos filhos quando o outro genitor se afasta dos deveres parentais. Os guardiães reclamaram que precisam conciliar seu tempo com o trabalho, a casa, a vida pessoal e os filhos. Ressaltaram que essa é uma dificuldade vivenciada exclusivamente pelo guardião, pois aquele que não detém a guarda pode desfrutar do lazer, já que não possui obrigação do cuidado diário com as crianças. O único pai guardião que participou dos grupos, concordando com a queixa, destacou o quanto é difícil para muitos homens perder o espaço pessoal em detrimento do cuidado dos filhos.
Certos pais consideravam que, por vezes, quando a mulher detém a guarda, a ligação desta com os filhos ou com um dos filhos se torna muito forte, e ela procura afastar, de qualquer maneira, o ex-marido da(s) criança(s). Nesse âmbito, mães contaram que, ao se voltar completamente para o(s) filho(s) após a separação, estavam se afastando de algo que as incomodava, ou seja, de pensar sobre o rompimento conjugal.

Os que não possuíam a guarda dos filhos deixavam transparecer, certas vezes, dúvidas a respeito de como lidar com as crianças nos dias de visita, ou ainda, de qual papel deveriam exercer. Mostravam-se desapontados com o fato de, regularmente, os filhos preferirem ficar em casa, achando que - ao estilo da expressão pai de fim-desemana -deveriam cumprir um roteiro de atividades fora do ambiente doméstico com as crianças, sentindo-se rejeitados quando não concordavam com a programação de lazer pré-definida. Já para os guardiães, se as crianças fossem para a casa do visitante "para não fazer nada", ou seja, não sair, não passear, seria melhor não ir. Enquanto alguns pais que não eram guardiães lamentavam que, com visitas quinzenais, não podiam corrigir os filhos no que consideravam necessário, admitindo que o vínculo que permite a intimidade é cumulativo, aqueles que possuíam a guarda reconheciam o vazio que se estabelecia no final de semana em que os filhos estavam com o outro genitor.

Os homens citaram algumas situações que não são socialmente facilitadas, como o fato de um pai, quando está sozinho e fora de casa, precisar levar uma filha pequena ao banheiro, relato que surpreendeu algumas mães. Dificuldades também foram narradas sobre meninas pequenas que querem levar, para a casa do pai, amiguinhas para brincar.

Os gastos financeiros com os filhos foram destacados pelo grupo de genitores guardiães 
Como expõem

Poussin e Lamy

(2005), ao

abordarem a

participação

equânime de

pais e mães nos

cuidados com

os filhos após

a separação

conjugal: "É...

uma boa forma

de lembrar aos

pais negligentes

quais são suas

responsabilidades,

e aos pais

excluídos $(e$

aos seus ex-

companheiros)

quais são os seus direitos" (p. 18). como causa de discórdia entre o ex-casal. Alegaram que, na maioria das vezes, a pensão que os filhos recebem não é suficiente para pagar boa parte das despesas destes. Além disso, os guardiães acabam sendo estigmatizados, acusados de utilizar a guarda dos filhos para conseguir vantagens econômicas. Nessa discussão, apesar de geralmente ser dado destaque à redução nos recursos financeiros gerenciados pelas mulheres após o divórcio, destaca-se que os genitores que não permaneceram com a guarda também relataram as sérias dificuldades econômicas por que passaram após a separação, o que retardava, inclusive, a aquisição de bens móveis necessários à organização de um novo lar. Tais queixas podem remeter à discussão sobre a perda do poder aquisitivo de diversos segmentos da população, mesmo aqueles considerados de classe média. Quando o casal reside junto, de alguma forma, os salários se somam; no entanto, quando separados, qualquer fração descontada acarreta déficit no orçamento.

Alguns participantes dos grupos, principalmente os que não possuíam a guarda, eram favoráveis à guarda compartilhada, pois compreendiam que, assim, aquele que reside com a criança não seria o todopoderoso, como expressavam. Defendiam essa modalidade de guarda por entenderem que, dessa maneira, pai e mãe seriam detentores das mesmas responsabilidades no cuidado com os filhos. Os poucos pais que não possuíam conhecimentos sobre a guarda compartilhada recebiam explicações de outros integrantes do grupo quando solicitavam artigos e reportagens que abordassem o assunto. Quanto a essa modalidade de guarda, diversos autores reconhecem sua importância (Brito, 2005; Poussin \& Lamy, 2005), interpretando que a mesma transmite aos pais o entendimento que, após a separação, não haverá um genitor principal. Como expõem Poussin e Lamy (2005), ao abordarem a participação equânime de pais e mães nos cuidados com os filhos após a separação conjugal: "É... uma boa forma de lembrar aos pais negligentes quais são suas responsabilidades, e aos pais excluídos (e aos seus ex-companheiros) quais são os seus direitos" (p. 18).

Espera-se, portanto, que, ao se adotar a guarda compartilhada, diversas queixas e situações aqui apontadas pelos pais não façam mais parte do cotidiano daqueles que se separam. Compreende-se também que, com essa modalidade de guarda, os pais terão de se organizar a partir de outro parâmetro: a responsabilização conjunta dos cuidados e da educação de filhos.

\section{O acesso aos filhos}

Como também constatado na pesquisa conduzida por Décoret (2001), os homens reclamaram, principalmente, do afastamento dos filhos após a separação e do excesso de atribuições da ex-esposa na educação das crianças. Já as mulheres lamentavam o fato de os ex-maridos procurarem pouco os filhos, o que lhes acarretava sobrecarga, pois precisavam resolver, sozinhas, tudo o que dizia respeito às crianças.

As queixas paternas quanto ao controle que mães pretendem exercer sobre as crianças, mesmo nos dias e horários em que elas se encontram na companhia dos pais, foram veementes. Explicaram que é comum a criança receber uma série de ligações telefônicas da mãe com inúmeras recomendações, sendo que, nesses momentos, acham que aproveitam para conferir se a criança comeu ou se tomou banho, avaliando como os pais estão desempenhando seu papel, o que, segundo entendem, os desqualifica perante os filhos. Ao abordar o assunto, muitas mães relataram que não conseguem se desligar dos filhos, mesmo quando estão com os pais, pois compreendem que devem exercer seu papel de guardiãs durante 24 horas. Tal afirmação 
faz recordar o artigo de Muzio (1998), no qual a autora expõe que: "A maternidade foi, historicamente, a via de realização das mulheres" (p. 171). Aponta-se também a naturalização, que perdurou por longo período, da ideia de que as mulheres seriam portadoras de instinto materno (Badinter, 1985).

Alguns pais mencionaram que muitos homens, ao contrário do que se pensa, gostam de cuidar dos filhos, porém possuem maneira de executar a tarefa diferente das mulheres, o que não quer dizer que seja inadequada. Ainda quanto a esse aspecto, certas mães reconheceram que não costumavam deixar os filhos pequenos aos cuidados do ex-marido, pois não confiavam nas habilidades deste quanto ao trato infantil. Por essa razão, procuravam estar junto dos filhos nas visitas que o ex-marido fazia às crianças. Tais afirmações remetem ao entendimento de que, ao se manter a mulher no posto de rainha do lar ou daquela que tudo sabe sobre o cuidado de crianças, se contribui para "eternizar sua subordinação" -, utilizando-se, aqui, expressão empregada por Bourdieu (1999) -, na medida em que os papéis femininos prioritários continuam a ser vistos como aqueles relacionados ao espaço privado.

As mães que possuíam filhos adolescentes, ou adultos, ressaltaram o quanto foi difícil enfrentarem, sozinhas, problemas que ocorreram na adolescência dos mesmos. Admitiram que a ajuda do ex-cônjuge pode ser de grande valia, até mesmo para dividir responsabilidades e preocupações. Aconselharam às outras mães com filhos menores que pensassem em não afastar $\mathrm{o}$ pai do convívio das crianças, para que este pudesse estar presente em momentos críticos do desenvolvimento dos filhos.

O uso da expressão deixar o filho sair ou ficar com o pai foi muito criticado pelos homens ao argumentarem, mais uma vez, que as mães se veem como principais responsáveis pelas crianças. Perante tal reclamação, mulheres que participaram dos grupos concordaram que essa é uma questão cultural e que acabam agindo como se estivessem fazendo um favor ao ex-marido. Curioso foi notar, também, que alguns homens se mostravam receosos em deixar os filhos residir apenas na companhia materna. Esses pais expressavam o medo de que as ex-mulheres não soubessem agir em situações de perigo ou de risco para as crianças, reproduzindo o estereótipo de que o homem deve salvar as crianças dos perigos da rua.

Muitos homens se queixavam de que não possuíam voz em relação às decisões da vida de seus filhos. Explicavam que, por vezes, a família materna e os empregados se preocupavam em restringir o contato e as ações do pai aos esparsos dias de visita estabelecidos. Em decorrência, alguns revelaram ter pensado em formar nova família e ter outros filhos para, assim, poderem exercer a paternidade, enquanto outros, resignados, tentavam explicar que era preciso aceitar e se conformar, pois essa era a realidade.

Como no julgamento de Salomão, alguns pais justificavam que, por vezes, a renúncia às visitas ocorria em nome do amor ao filho, e não por desprezo a ele. Como eram constantes e violentas as brigas com a exmulher, sendo necessário recorrer à Justiça para garantir o direito de visita, acabavam por se distanciar dos filhos por considerarem que a tensão e o desgaste emocional que a situação trazia eram prejudiciais tanto a eles como às crianças. Outra motivação alegada para um afastamento temporário dos filhos foi a acentuada queda no padrão financeiro e o fato de que, geralmente, são os homens que saem de casa, ficando sem residência e sem pertences domésticos. Por isso, alguns se sentiam pouco à vontade para receber os 
filhos em uma moradia improvisada, muito diferente da que residiam anteriormente.

Muitos pais também abominavam a designação, corriqueira, de visitantes dos filhos, ressaltando e insistindo que continuavam a ser pais. Compreendiam que a imagem do chamado pai visitante é denegrida pela sociedade. Para os homens, quando a mulher é colocada como visitante, a interpretação corrente é que deve ter cometido algo muito grave que a impediu de ficar com a guarda dos filhos, ou seja, deve ter sido culpada pela separação. Informaram, ainda, que quando o pai é o visitante, acontece de a genitora da criança desqualificar a imagem daquele junto a diversas instituições e aos profissionais especializados que realizam atendimentos sistemáticos dos filhos, reduzindo-se, dessa forma, a possibilidade de participação do pai no cotidiano da criança. Foram narradas diversas situações em que as mulheres não permitiam que os ex-cônjuges entrassem em contato com o médico dos filhos, ou ainda que soubessem quem era o psicólogo que atendia a criança, usando os filhos como arma em um campo de batalha que parecia sem fim, como narravam os pais.

Inúmeras foram as reclamações dos homens quanto à dificuldade em participar de atividades escolares, como festas e reuniões na instituição onde os filhos estudavam. Segundo o relato dos pais, em determinados casos, as escolas, seguindo o que fora solicitado pelas mães, não forneciam informações sobre as crianças e sobre o calendário de atividades, dado também observado por Cardoso (2008) em pesquisa que desenvolveu sobre o tema. Para esses homens, algumas instituições escolares não percebem a dimensão do problema, deixando de lado as dificuldades pelas quais passaram os filhos de pais separados. Alguns pais, inclusive, ao se dirigirem ao colégio dos filhos, notaram que as ex-esposas não haviam preenchido, na ficha de matrícula, o nome do pai da criança, chegando a omitir o sobrenome paterno dos filhos.

Buscando evitar tais situações, bem como reconhecendo o direito de pai e mãe participarem das atividades escolares, foi aprovada, no Distrito Federal, a Lei Estadual no 3.849, de 2006, que institui para os estabelecimentos de ensino fundamental e médio a obrigatoriedade em encaminhar a ambos os pais ou responsáveis, conviventes ou não, todas as informações referentes à vida escolar dos filhos e/ou dependentes. Em 2009, após aprovação de lei federal, essa orientação foi incluída na Lei de Diretrizes e Bases da Educação, valendo para todo o território nacional.

Todos os participantes dos grupos demonstraram receio quanto ao relacionamento dos filhos com o(a) novo(a) companheiro(a) do(a) ex-cônjuge. De certa forma, mostravamse ameaçados em seus papéis materno e paterno, fato que parecia mais acentuado para aqueles que não ficaram residindo com os filhos. O novo casamento parecia trazer confusão quanto aos papéis e atribuições de cada um dos adultos com as crianças. Assim, muitos pais reclamavam que os filhos passavam mais tempo com o padrasto do que com eles, enquanto muitas mães não suportavam que os filhos pequenos se referissem à namorada do pai.

\section{Avaliação sobre o funcionamento dos grupos}

Como avaliação final, muitos pais e mães sinalizaram que o encontro com pessoas que vivenciavam problemas semelhantes os ajudou a ver a própria situação de outra maneira, indicando-lhes alternativas, caminhos e possibilidades de luta que não o simples enfrentamento com o ex-cônjuge. Em diversos encontros, foi ressaltada a importância da troca de experiências entre 
guardiães e aqueles que não residiam com os filhos bem como de ouvirem as queixas e os receios dos outros, pois, se o lamento partisse de seus ex-cônjuges, o conceituariam como implicância. Justificaram melhor compreensão do que se passava no contexto pós-divórcio a partir do relato e das explicações dos presentes na atividade. Os integrantes dos grupos reconheciam que precisavam falar e discutir suas preocupações em relação ao comportamento dos filhos e as implicações decorrentes da separação conjugal. No entanto, notavam que amigos e familiares não queriam ouvir esse tipo de assunto, e que, sozinhos, era árduo suportar todos os obstáculos que se apresentavam.

Concluíram que, como participantes do grupo, havia sido possível refletir sobre assuntos e situações em que, até então, não haviam parado para pensar, lidando de forma diferenciada em relação a algumas questões e, inclusive, dialogando melhor com o exparceiro. Alguns revelaram que ampliaram sua luta para maior contato com os filhos, sentindo-se mais seguros e esclarecidos sobre uma série de assuntos comuns àqueles que se separam. Outros se engajaram em lutas coletivas que visavam à mudança da legislação, fornecendo depoimentos em programas de televisão e atuando em organizações não governamentais que buscam a igualdade de direitos de pais e mães separados. Houve também procura por atendimento terapêutico.

Assim, consideraram que foi possível sair da imobilidade e da posição de vítima, a partir do entendimento de que há diversas pessoas que passam pelas mesmas dificuldades, o que motiva a busca por mudanças. Por tais razões, apontaram a pertinência e a adequação de um espaço para reuniões, debates e divulgação de informações sobre o tema. Sugeriram também a composição de grupos de autoajuda, visando à troca de experiências, bem como a redação e a divulgação de cartilhas que possam explicar e orientar os pais sobre a importância da guarda compartilhada.

O grupo também solicitou, da equipe de pesquisa, que o tema referente ao exercício dos papéis parentais após o desenlace conjugal fosse abordado em outros espaços da sociedade, como nas escolas, nos Tribunais de Justiça e em outras universidades, principalmente junto aos cursos de Pedagogia e de Direito. Entendem que os profissionais que atuam diretamente com crianças e aqueles que trabalham com o Direito de família deveriam receber mais esclarecimentos a respeito das dificuldades que pais e filhos enfrentam após a separação conjugal.

\section{Conclusão}

Por meio da pesquisa desenvolvida, foi possível observar que o oferecimento de grupos de reflexão a pais e mães separados pode ser, além de técnica para a coleta de dados, mais um recurso à disposição daqueles que passam por dificuldades após o rompimento conjugal. $\mathrm{Na}$ atividade, pais e mães podem relatar e debater temas e situações relacionados às suas vivências com os filhos após a separação conjugal, trocando experiências, solicitando explicações, ouvindo soluções diversas encontradas por distintas pessoas e, entre outros, sugerindo possibilidades de engajamentos em lutas sociais.

Notou-se que as dificuldades pelas quais podem passar pais e mães após a dissolução conjugal despontam, geralmente, encobertas pelo manto do enfrentamento e de acusações entre homens e mulheres. No entanto, no transcorrer dos encontros, houve a possibilidade de se perceber que muitos problemas parecem enraizados em arranjos de guardas monoparentais, que qualificam um dos genitores como visitante dos filhos após a separação conjugal. 
Na pesquisa, foi evidenciada a similaridade de queixas proferidas por aqueles colocados em cada uma das categorias - na de guardiães e na de não residentes com os filhos. A visão, ainda culturalmente marcante, que atribui às mulheres a primazia no cuidado dos filhos, conduzindo-as frequentemente ao lugar de guardiãs, contribui para solidificar e identificar uma série de questões como próprias de comportamentos femininos, ao mesmo tempo em que se interpretam situações decorrentes da chamada visitação como específicas de homens. Dessa forma, passa-se a atribuir ao comportamento, ou à natureza de homens e mulheres, as inadequações no convívio que se estabelece com os filhos após a separação conjugal.

No que diz respeito aos problemas e queixas narrados pelos componentes dos grupos, cabe esclarecer que, no presente trabalho, não se teve a intenção de generalizar situações ou comportamentos que ocorreriam como desdobramento de uma separação conjugal. Compreende-se, todavia, que os dados obtidos na pesquisa podem colaborar com o mapeamento de campos de dificuldade que possam surgir nessas situações. Destaca-se também que, ao longo do trabalho com os grupos, o entendimento inicial de alguns pais de que os impasses que atravessavam seriam particulares pôde ser reinterpretado. Assim, além das questões próprias de cada família, percebiam impasses sociais, o que os levou a concluir pela necessidade de reivindicar, à sociedade e às suas diversas instituições, mudanças que contemplem a pluralidade de modelos familiares próprios do contexto contemporâneo.

Considera-se que a família pós-divórcio pode passar por problemas específicos, necessitando de ajuda qualificada de profissionais. Nessa atuação, conclui-se que o uso dos grupos de reflexão pode facilitar a compreensão de problemas comuns àqueles que desfazem o vínculo conjugal, envolvendo também pais e mães na luta, individual e coletiva, por melhores condições de convivência.

Leila Maria Torraca de Brito

Professora Adjunta do Instituto de Psicologia da Universidade do Estado do Rio de Janeiro (UERJ). Doutora em Psicologia pela Pontifícia Universidade Católica do Rio de Janeiro, Rio de Janeiro - RJ - Brasil.

E-mail: torraca@uerj.br

Andréia Ribeiro Cardoso

Doutora em Psicologia Social pela Universidade do Estado do Rio de Janeiro,

Rio de Janeiro - RJ - Brasil.

E-mail: andreiarcard@gmail.com

Juliane Dominoni Gomes de Oliveira

Mestre em Psicologia Social pela Universidade do Estado do Rio de Janeiro, Rio de Janeiro - RJ - Brasil.

E-mail: julianedominoni@gmail.com

Endereço para envio de correspondência:

Rua São Francisco Xavier 524, 10 andar, sala 10.001-B. Maracanã, Rio de Janeiro - RJ - Brasil CEP 20550-900.

E-mail: torraca@uerj.br

Recebido 9/9/2009, 1a Reformulação 10/3/2010, Aprovado 3/4/2010. 


\section{Referências}

Acosta, F., Andrade Filho, A., \& Bronz, A. (2004). Conversas homem a homem: grupo reflexivo de gênero. Rio de Janeiro: Instituto Noos de Pesquisas Sistêmicas e Desenvolvimento de Redes Sociais.

Badinter, E. (1985). Um amor conquistado: o mito do amor materno. Rio de Janeiro: Nova Fronteira.

Bardin, L. (1977). Análise de conteúdo. Lisboa: Edições 70.

Brasil. (2002). Lei $n^{\circ}$ 10.406, de 10 de janeiro de 2002. Institui o Código Civil. Brasília, DF: Autor.

Brasil. (1990). Lei $n^{\circ}$ 8.069, de 13de julho de 1990. Institui o Estatuto da Criança e do Adolescente. Brasília, DF: Autor.

Brito, L. M. (2002). Impasses na condição da guarda e da visitação - o palco da discórdia. In Instituto Brasileiro de Direito de Família (Org.), Anais do III Congresso Brasileiro de Direito de Família (pp. 433-448). Belo Horizonte: Del Rey-IBDFAM.

Brito, L. M. (2005). Guarda compartilhada: um passaporte para a convivência familiar. In Apase (Org.), Guarda compartilhada: aspectos psicológicos e jurídicos (pp. 53-71). Porto Alegre: Equilíbrio.

Brito, L. M., \& Gonsalves, E. N. (2009). Razões e contra-razões para aplicação da guarda compartilhada. Revista dos Tribunais, (886), 69-86.

Bourdieu, P. (1999). A dominação masculina. Rio de Janeiro: Bertrand Brasil.

Bruno, D. (2003). Direito de visita: direito de convivência. In G. Groeninga \& R. S. Pereira (Orgs.), Direito de família e psicanálise: rumo a uma nova epistemologia (pp. 311-324). Rio de Janeiro: Imago.

Cardoso, A. R. (2008). A escola diante da família pós-divórcio. In L. Brito (Org.), Famílias e separações: perspectivas da psicologia jurídica (pp. 49-80). Rio de Janeiro: EdUERJ.

Connel, R. W. (2003). La organización social de la masculinidad. In C. Lomas (Ed.), Todos los hombres son iguales? (pp. 31-54). Buenos Aires: Paidós. (Trabalho original publicado em 1995)

Décoret, B. (2001). Organisation parentale et persistance du lien après divorce. Recherche ethnométhodologique avec des divorcés. Dialogue, 151(1), 39-49.

Durning, P. (1996). Les aides aux parents. In G. Neyrand (Ed.), La famille malgré tout. Panoramiques, 25(2), 191-195.

Gillot, D. (1998). Familles: la victoire des nouveaux couples. Nouvel Observateur, (1753), 10-18.

Instituto Brasileiro de Geografia e Estatística. (2005). Estatísticas do Registro Civil do ano de 2005. Recuperado em 21 de outubro de 2006, de http://www.ibge.gov.br

Karan, M. L. (1998). A superação da ideologia patriarcal e as relações familiares. In P. Silveira (Org.), Exercício da paternidade (pp. 185-192). Porto Alegre: Artes Médicas.

Lehr, R., \& MacMillan, P. (2001). Dealing with divorce. The psychological and emotional impact of divorce: The noncustodial fathers' perspective. Families in society. The Journal of Contemporary Human Services, 82(4), 373-382.

Muzio, P. (1994). Virilidad: conocemos el costo de ser hombre? Cadernos de Psicologia, 8, 19-44.
Muzio, P. (1998). Paternidade (ser pai)... para que serve? In P. Silveira (Org.), Exercício da paternidade (pp. 165-174). Porto Alegre: Artes Médicas.

Pereira, R. (2003). Pai, por que me abandonaste? In G. Groeninga \& R. S. Pereira (Orgs.), Direito de família e psicanálise: rumo a uma nova epistemologia (pp. 219-228). Rio de Janeiro: Imago.

Poussin, G., \& Lamy, A. (2005). Custodia compartida. Espanha: Espasa Calpe.

Rapizo, R., Falcão, C., Costamilan, M. B., Scodro, M., \& Moritz, N. (1998). A construção da parentalidade pós-divórcio: uma vivência feminina. Nova Perspectiva Sistêmica, 12, 32-38.

Rapizo, R., Costamilan, M. B., Moritz, N., \& Hinds, S. (2001) Continuando a experiência: os grupos de mulheres e filhos que viveram o divórcio. Nova Perspectiva Sistêmica, 19, 36-42.

Rose, D. (2001). Retour sur les méthodologies de recherche féministe: Document de travail. Condition féminine Canadá. Recuperado em 06 de julho de 2001, de http://www.swccfc.gc.ca

Soares, A. B., Martins, A. C., Butler, U. M., Caldeira, P., \& Rizzini, I. (2003). Trajetórias de vida de crianças e adolescentes nas ruas do Rio de Janeiro. In I. Rizzini (Ed.), Vida nas ruas: crianças e adolescentes nas ruas: trajetórias inevitáveis (pp. 123-272). Rio de Janeiro: Ed. PUC-Rio.

Teubal, R. (2005). Factores de cambio en los grupos y aportes para la intervención. Revista Topia $\_$43, 14-15.

Wallerstein, J., \& Kelly, J. (1998). Sobrevivendo à separação: como pais e filhos lidam com o divórcio (M. A V. Veronese, trad.). Porto Alegre: Artmed. (Trabalho original publicado em 1996)

Wallerstein, J., Lewis, J., \& Blakeslee, S. (2002). Filhos do divórcio (W. Fuchs, trad.) São Paulo: Loyola. (Trabalho original publicado em 2000) 